\title{
Opportunity or Crisis? Volatility and Leverage Effect in the World's Largest Economies
}

\author{
Amalendu Bhunia \\ Professor of Commerce, Department of Commerce \\ University of Kalyani, West Bengal, India
}

Tel: 33-2582-8750/Ext. 354

\begin{abstract}
Devrim Yaman (Corresponding author)
Associate Dean and Robert J. Bobb Professor of Finance, Haworth College of Business

Western Michigan University, Kalamazoo, MI 49008-5457, USA

Tel: 1-269-387-5058Ｅ-mail: devrim.yaman@wmich.edu
\end{abstract}

Received: September 2, 2019 Accepted: September 20, 2019 Published: October 11, 2019

doi:10.5296/ijafr.v9i4.15609

URL: https://doi.org/10.5296/ijafr.v9i4.15609

\begin{abstract}
This paper examines the relationship between asset volatility and leverage for the three largest economies (based on purchasing power parity) in the world; US, China, and India. Collectively, these economies represent Int $\$ 56,269$ billion of economic power, making it important to understand the relationship among these economies that provide valuable investment opportunities for investors. We focus on a volatile period in economic history starting in 1997 when the Asian financial crisis began. Using autoregressive models, we find that Chinese stock markets have the highest volatility among the three stock markets while the US stock market has the highest average returns. The Chinese market is less efficient than the US and Indian stock markets since the impact of new information takes longer to be reflected in stock prices. Our results show that the unconditional correlation among these stock markets is significant and positive although the correlation values are low in magnitude. We also find that past market volatility is a good indicator of future market volatility in our sample. The results show that positive stock market returns result in lower volatility compared to negative stock market returns. These results demonstrate that the largest
\end{abstract}


economies of the world are highly integrated and investors should consider volatility and leverage besides returns when investing in these countries.

Keywords: Leverage effect, Volatility, GARCH models, US stock market, Chinese stock market, Indian stock market

\section{Introduction}

The relationship between asset volatility and leverage effect has been a contentious topic in recent finance literature. Prior studies show that volatility and asset returns are generally negatively interrelated; when volatility rises the stock price falls and vice-versa (Sood and Saluja, 2016). This relationship is commonly called the "leverage effect" (Black, 1976; Christie, 1982). Studies show that leverage intensifies stock return volatility significantly (Lithman, 2010). Volatility also increases when stock prices drop and decreases when stock price rise (Triady et al., 2016). To the extent that volatility is priced by market participants, an expected increase in volatility would increase the required rate of return on equity that in turn causes stock price to decline. The influence of news is asymmetric; negative news creates a bigger shock on volatility than positive news (Aboura and Chevallier, 2012). Hence, we typically observe a lower volatility in an upward market and a higher volatility in a downward market (Kristoufek, 2014) (Note 1).

In this paper, we study the relationship between volatility and leverage effects using autoregressive models. Beginning with Engle's (1982) Autoregressive Conditional Heteroskedasticity Model (ARCH), autoregressive models have been widely used to capture the time-varying characteristics of asset returns. In ARCH, the time-varying character of asset returns has been captured in the error terms of ordinary least squares regressions which are presumed to have a constant variance. In 1986, Bollerslev introduced the Generalized Autoregressive Conditional Heteroskedasticity (GARCH) model, which was followed by the Exponential GARCH (EGARCH) model introduced by Nelson in 1991. EGARCH model allows us to capture the asymmetric impact of negative and positive information on stock volatility mentioned above. EGARCH also captures the negative association variance and stock returns, the leverage effect (Turan, 2016). The GJR-GARCH introduced by Glosten, Jagannathan and Runkle in 1993 is able to distinguish between the positive and negative impacts. In our study, we utilize all of these models and choose one developed stock market and two developing stock markets in order to provide a comprehensive analysis on the relationship between volatility and leverage effects.

We are intentional in our choice of stock markets. Asian markets provide valuable opportunities for investors. The rise of the middle class in this region allowed consumption levels to continue to grow, creating many pockets of economic expansion. For example, although the economic expansion in China is slowing, the growth in GDP is still strong. This country has a strong domestic consumption and low valuations. There have been numerous reforms in the economy, particularly in the state-owned enterprises. India is also attracting investors due to the optimism in the future prospects of this country and this has helped the valuations of the stocks. The growth prospects of India are good in part due to the declining commodity and oil prices since this country is an importer of commodities and oil. 
In this study, using of returns Dow Jones Industrial Average, Shanghai Composite Index, and BSE Sensex we show that the unconditional correlation among the US, Chinese, and Indian stock markets is positive. Our results indicate that positive stock market returns result in lower volatility compared to negative stock market returns. We find that the Chinese stock markets have the highest volatility among the three stock markets while the US stock market has the highest average returns. The Chinese stock market is also less efficient than US and Indian stock markets since the impact of new information takes longer to be reflected in stock prices.

The paper is organized as follows: in the next section, we review the literature on the causal relationship between volatility and leverage. In section 3, we describe our empirical analysis, including our data, methodology, and results. In section 4, we summarize our conclusions.

\section{Literature Review}

Prior research on volatility and leverage has mostly been empirical in nature with a few theoretical studies in this area. Many of the empirical studies focused on groups of countries while others studied a single country.

Two examples of theoretical papers in this research area are Aydemir et al (2007) and Guo et al. (2011). Aydemir et al. study the relationship between stock volatility and financial leverage in an economy with realistic market risk price and interest rate. The authors study the effect of leverage both at a firm level and at a market level where the firm is exposed to both firm and market risks. Aydemir et al. show that financial leverages increases the level of equity volatility for the market as a whole. However, the time-varying interest rate and market price is what drives the dynamics of equity volatility. At the market level, financial leverage does not have a large effect on the dynamics of stock return volatility. The contribution of financial leverage to the dynamics of stock return volatility of a small firm is greater.

In their paper, Guo et al develop a general equilibrium model of asset trading in the existence of leverage. In the model, investors can engage in speculative trading with diverse beliefs about the fundamental value of the assets. The authors show that when the leverage ratio increases, the stock price increases as well in the current period. In the subsequent period, there is more borrowing and more stock purchase that increases the stock price. The study provides some support to the argument that when the shock is unanticipated, decreasing financial leverage can stabilize the market, although this argument lacks solid theoretical foundation.

Chelley-Steeley and Steeley (2005) and Krishnan and Mukherjee (2010) study single countries in detail. In their paper, Chelley-Steeley and Steeley study the relationship among the leverage, return volatility, and size of UK companies. The authors show that volatility responds more to bad news in the form of negative returns than to good news in the form of positive returns indicating that there is a negative relation between the volatility of capitalization-sorted portfolios and stock returns of UK companies. When they examine the leverage ratios of the companies in the capitalization portfolios, the authors find that high 
leverage ratios are more likely to be found in portfolios with smaller firms. There is no evidence that shocks to smaller firm volatility influences the larger firm portfolio but shocks to the volatility of larger firms have significant influence on the conditional mean and conditional volatility of small firms.

In their paper, Krishnan and Mukherjee (2010) focus on the Indian stock market. The authors utilize daily data on the NIFTY index for 1996-2006 and estimate a set of GARCH models. Krishnan and Mukherjee use the LR test to select a possible model they have identified through Box-Cox power transformations to nest GARCH models. Their models show that the standard symmetric GARCH model does not explain the conditional volatility in the Indian stock market due to the presence of asymmetry in this market. The authors also show that non-trading days are important, contributing to volatility as much as one-fourth of the volatility of the trading days. Krishnan and Mukherjee find that the non-standard, non-linear GARCH model fits the time-varying volatility data better than the standard asymmetric models.

Among the studies that analyze a group of countries, Okicic (2014) and El Alaoui et al. (2017) study European countries. Okicic focuses on Central and Eastern Europe and find that negative shocks increase the volatility of stock returns more than positive shocks, pointing to the existence of a leverage effect. The author also finds that for companies in this region, the mean and volatility dynamics can be approximated by ARIMA and GARCH processes. The results show that investors can use historical data to earn gains above the average, indicating the existence of stock market inefficiency.

El Alaoui et al. (2017) study the leverage effect on the returns and volatility of stocks and stock portfolios. The authors find that the firm's volatility and stock returns change significantly when capital structure changes. When the authors examine Islamic-compliant stocks separately, they find that these stocks do not show significant differences in returns but on average they have less volatility. The authors also show that in terms of risk-return profiles, Islamic-compliant portfolios show less volatility than high debt portfolios. While the study finds no evidence of negative impact of sovereign debt on returns and volatility at the firm-level, there is strong evidence of negative effect of S\&P European stock market index volatility.

The studies of Bala and Premaratne (2004), Yalama and Sevil (2009), Xu and Li (2012), Tripathy (2017), and Jin (2017) cover larger geographical areas. Bala and Premaratne (2004) study the volatility and leverage effects in Singapore, US, UK, Hong Kong, and Japan. The authors argue that studying leverage and investment decisions is important as volatility is "synonymous with risk". Bala and Premaratne find that the leverage effect is higher in the Singapore stock market compared to the other markets in their sample. This result shows that bad news has more influence on the Singapore stock market than the other markets. Bala and Premaratne also show that the co-movement between the Singapore stock market and the other markets is high. There is significant volatility spillover from the Singapore stock market to the other markets. This result shows that spillovers are possible from small markets to 
large markets, contradicting prior evidence that indicates volatility spillovers are unidirectional from the dominant market to the smaller market.

Yalama and Sevil (2009) examine the leverage effect on the expected returns of European, Asian, and US markets using the E-GARCH model as well as study the relationship between expected return and volatility using he GARCH-M method. The authors show that the leverage effect is negative and statistically significant for all markets except for ISE-100 index. This finding indicates that bad news (negative returns) are more likely to be associated with larger volatility than good news (positive returns). Yalama and Sevil also show that there is no significant relationship between expected returns and volatility for the markets they analyze.

$\mathrm{Xu}$ and $\mathrm{Li}$ (2012) use realized volatility as a proxy for true volatility in a stochastic volatility estimation and study the leverage effect. Their sample consists of the European and US stock indices. They show that in terms of the Bayesian Information Measures, the leveraged stochastic volatility model is preferred to the model without the leverage effect. $\mathrm{Xu}$ and $\mathrm{Li}$ detect the leverage effect significantly and consistently among all realized volatility construction methods and at each sampling frequency level. At lower sampling frequency the volatility persistence is less due to the noise.

Tripathy (2017) studies leverage effects on the volatility of Brazil, Russia, India, and China (BRIC). She finds that both recent and past news affect the stock market volatility of the BRIC countries. Tripathy shows that the stock market volatility bad news reduces stock returns and increases stock market volatility and finds that stock price declines are more influential on subsequent volatility than stock price increases. Another finding of the paper is that investors can analyze past market news and predict the future market movements, thereby making a profit by strategizing their investments. Tripathy shows that the volatility of the stock markets of BRIC countries tends to move together, although there are short- and long-term variations in the volatilities.

Studying 16 Asian, European and US, Jin (2017) shows that there is a negative relationship between volatility and returns in these markets. After examining lead-lag relations between stock returns and volatility, Jin shows that the main source of this negative correlation is the leverage effect. Jin uses a "rolling window approach" to examine the dynamic nature of the volatility-return relationship and shows that when returns decline, the time-varying negative volatility-return relationship is more prone to generating an asymmetric response with a greater effect. In periods of market turbulence, the return-volatility relation is stronger.

The existing literature has shown the importance of volatility in certain countries and regions. However, none of the studies has demonstrated if the volatility effect exists in the largest and hence most influential economies in the world. They also do not show how these most influential economies affect each other and if there are diversification benefits of investing in these markets. By studying the three largest economies in the world, we contribute to the existing literature in this area. 


\section{MlMacrothink}

International Journal of Accounting and Financial Reporting

ISSN 2162-3082

2019, Vol. 9, No. 4

\section{Empirical Analysis}

\subsection{Data}

We use daily returns based on the closing prices of the indices in our sample. We use Dow Jones Industrial Average returns to measure the performance of the US stock markets, Shanghai Composite for China, and BSE Sensex for India. We obtain our index return data from Yahoo.com. In order to capture the impact of volatility on markets, we start our sample period on July 1, 1997, the day before the Asian financial crisis started. Our sample period ends on November 22, 2018. We use autoregressive models to measure volatility and leverage effects. The description of the models and our results using them is below.

Table 1 shows the descriptive statistics of the daily stock market returns of the three stock markets in our sample. In this table, we first transform the daily stock price series to their natural logarithms, allowing the returns to have a linear time-series behavior rather than an exponential behavior. We find that the US stock market had the highest return (0.0034) while the Chinese stock market had the lowest return (0.0025) in the sample period. During the sample period, Sensex had the highest daily return as well as the lowest daily return. The table shows that the Shanghai Composite Index is most volatile with a standard deviation of 0.2047 , followed by Sensex with a standard deviation of 0.1698 . The standard deviation of returns for Dow Jones Industrial Average is 0.1231, making it the least volatile market. The skewness statistics for all three markets is between -0.5 and 0.5 , indicating that the distributions of index returns in these markets are approximately symmetric. However, since the kurtosis value exceeds 3 for all three markets, the distributions of the returns are leptokurtic with large differences in the returns, an indication of volatile markets. The Jarque-Bera statistics illustrate that none of the stock index returns in our sample are normally distributed. This result indicates the inter-temporal dependence in the moments of the index returns (Bala and Premaratne, 2004).

Table 1. Descriptive statistics

\begin{tabular}{llll}
\hline & LNDJIA & LNSSE & LNSX \\
\hline Mean & 0.0033 & 0.0025 & 0.0030 \\
\hline Maximum & 1.1621 & 1.2831 & 1.6998 \\
\hline Minimum & -0.8973 & -0.6356 & -1.3843 \\
\hline Standard Deviation & 0.1231 & 0.2047 & 0.1698 \\
\hline Skewness & -0.1395 & -0.0454 & -0.0993 \\
\hline Kurtosis & 7.6052 & 11.5086 & 9.6168 \\
\hline Jarque-Bera & 7254.78 & 16790.87 & 9845.32 \\
\hline Number of Observations & 5,387 & 5,353 & 5,392 \\
\hline
\end{tabular}




\section{MN Macrothink}

International Journal of Accounting and Financial Reporting

ISSN 2162-3082

2019, Vol. 9, No. 4

This table shows the descriptive statistics of the stock market indices in our sample. Our sample consists of stock indices from US, China, and India. We take the natural logarithm of the daily prices of these indices and denote these prices as LNDJIA for Dow Jones Industrial Average (US), LNSSE for Shanghai Composite Index (China), and LNSX for Sensex (India).

\subsection{Empirical Analysis}

\subsubsection{Correlation}

We first study the time-invariant unconditional correlation coefficients between the stock market indices of the three countries in our sample. Studying correlations allows us to understand the extent of the integration among the stock markets, thereby shedding light on the extent of possible volatility transmissions from one country to another. Prior research shows that low correlation indicates that stock return movements are transmitted from the relatively smaller market to the larger market (Dahiru and Taro, 2017). Table 2 shows the unconditional correlation coefficient statistics for the daily stock market returns of the three stock indices we have selected. We find that all of the correlation coefficients we study are positive and significant at the $1 \%$ level. This result indicates that the three stock markets typically move together. The table shows that, although statistically significant, the correlation coefficients are low in general. The correlation coefficient between the US and Indian stock markets is highest (0.1308) followed by the correlation between the Indian and Chinese stock markets $(0.1176)$. The correlation between the US and Chinese stock markets was lowest with a coefficient of 0.11 , indicating that the portfolio diversification opportunities are highest when investors invest in these two stock markets.

Table 2. Unconditional correlation statistics

\begin{tabular}{llll}
\hline & LNDJIA & LNSSE & LNSX \\
\hline LNDJIA & $\begin{array}{l}1.0000 \\
(0.00)\end{array}$ & & \\
& 0.1100 & 1.0000 & \\
LNSSE & $(0.00)$ & & 1.0000 \\
\hline
\end{tabular}

This table shows the unconditional correlation coefficients between the stock market indices in our sample. Our sample consists of stock indices from US, China, and India. We take the natural logarithm of the daily prices of these indices and denote these prices as LNDJIA for Dow Jones Industrial Average (US), LNSSE for Shanghai Composite Index (China), and LNSX for Sensex (India). 


\section{MlMacrothink}

\subsubsection{GARCH Model}

In this section, we study how the GARCH model fits the returns of the three indices in our sample. Prior studies show that volatility can be transmitted among stock markets. Hence, we investigate how the volatility and leverage effects can be spread to other markets in our sample. We utilize the GARCH model, a model that recognizes the different types of risks, the leverage effect, and the long-term persistence of risk.

GARCH model is an extension of the ARCH model. The ARCH model is appropriate for time series data when the error variance follows an autoregressive pattern. In this model, we describe the error term for the current period as a function of the error terms of previous periods (lags). In many cases, the current period error term is related to the squares of the previous period error terms. The fundamental $\mathrm{ARCH}(\mathrm{q})$ model has a conditional mean and variance equation and both equations must be estimated concurrently as the variance is a function of the mean. A simple $\mathrm{ARCH}(1)$ with an autoregressive first order mean and variance equation is as follows,

$$
\begin{gathered}
\mathrm{y}_{\mathrm{t}}=\mathrm{u}_{\mathrm{t}} \\
\mathrm{u}_{\mathrm{t}} \sim \mathrm{N}\left(0, \mathrm{~h}_{\mathrm{t}}\right)
\end{gathered}
$$

Where, $\mu_{\mathrm{t}}$ is serially uncorrelated and has a zero mean. The conditional variance of $\mu_{\mathrm{t}}$, based on all obtainable information at time t-1 as specified in equation (2), equals $h_{t}$. Since the variance is the second moment of the method, it follows that the two equations represent a system. As a result, the mean is an $\mathrm{AR}(1)$ procedure and the variance is an autoregressive process of the first order. In this model, the distribution of the error term is not decided and the existence of the ARCH model indicates that the normal distribution is not always the best estimate (Sjo, 2011). We can represent the conditional variance as

$$
\mathrm{h}_{\mathrm{t}}=\alpha_{0}+\sum_{\mathrm{t}=1}^{\mathrm{q}} \alpha_{\mathrm{j}} \mathrm{u}_{\mathrm{t}-\mathrm{i}}^{2}
$$

In this equation $\alpha_{0}$ should be a positive parameter, $\alpha_{i} \geq 0$ and $i=1, \ldots, q$, although $\alpha_{0}$ may be negative. The ARCH model (2) is referred to as ARCH (q), where q refers to the order of the lagged squared returns included in the model. If we use ARCH (1), the model becomes

$$
\mathrm{h}_{\mathrm{t}}=\alpha_{0}+\alpha_{1} \mathrm{u}_{\mathrm{t}-1}^{2}
$$

Since $h_{t}$ is a conditional variance, its value must always be strictly positive; a negative variance at any point in time would be meaningless. All of the coefficients in the conditional variance are usually required to be non-negative. Thus, coefficients must be assure $\alpha_{0}>0$ and $\alpha_{0} \geq 0$. 


\section{Ml Macrothink}

International Journal of Accounting and Financial Reporting

ISSN 2162-3082

2019, Vol. 9, No. 4

If autoregressive moving average is more appropriate for the data, we use the GARCH model. This model is particularly useful when volatility is clustered and there are periods of calm as well as periods of high volatility. Since our sample period covers a volatile period of the Asian crisis as well as the following calm periods, this model is appropriate for our sample. This model allows for conditional variance where the current period's error term depends on the preceding lags, incorporating the latest information regarding the volatility from the earlier period in the form of $1^{\text {st }} \mathrm{lag}$ of the squared residual from the mean equation (Eleftherios et al., 2015). Bollerslev (1986) expanded the ARCH model into the Generalized $\mathrm{ARCH}$, allowing for past conditional variances in equations (2) and (4). GARCH (p,q) can be represented as:

$$
\mathrm{h}_{\mathrm{t}}=\alpha_{0}+\sum_{\mathrm{i}=1}^{\mathrm{q}} \alpha_{\mathrm{i}} \mathrm{u}_{\mathrm{t}-\mathrm{i}}^{2}+\sum_{\mathrm{i}=1}^{\mathrm{p}} \beta_{\mathrm{i}} \mathrm{h}_{\mathrm{t}-\mathrm{i}}
$$

Where, $h_{t}$ is a function of the lagged values of $\mu_{t-1}^{2}, \alpha_{0},\left\{\alpha_{i}\right\}, i=1, \ldots, p$ and $\left\{\beta_{i}\right\}, i=1, \ldots, q$ are positive constants. In this model, $\alpha_{0}>0, \alpha_{\mathrm{i}} \geq 0$ and $\beta_{\mathrm{i}} \geq 0$ for each $\mathrm{i}$ and have a weak stationary result if $\sum \alpha+\sum \beta<1$. If there are no ARCH or GARCH effects, the sum of the coefficients should be $0\left(\sum \alpha \mu_{t-1}^{2}+\sum \beta h_{t-1}=0\right)$. This indicates that the variable $\alpha_{0}$ is the residual variance and the sum of the coefficients $\sum \alpha+\sum \beta$ shows the long-run process of the GARCH model. If the coefficients sum to unity, $\sum \alpha+\sum \beta=1$, the model becomes an integrated GARCH model.

GARCH $(1,1)$ model is popularly used where the conditional variance is represented in the following way:

$$
h_{t}=\alpha_{0}+\alpha_{1} u_{t-1}^{2}+\beta_{1} h_{t-1}
$$

When we assume stationary covariance, the unconditional variance equation becomes

$$
\mathrm{h}=\alpha_{0}+\alpha_{1} \mathrm{~h}+\beta_{1} \mathrm{~h}
$$

and consequently

$$
\mathrm{h}=\frac{\alpha_{0}}{1-\alpha_{1}-\beta_{1}}
$$

For this unconditional variance to exist, it must be the case that $\alpha_{1}+\beta_{1}<1$ in the denominator.

In order for the variance to be positive, the condition $\alpha_{0}>0$ should be satisfied. Prior studies find that when we apply GARCH models to return series, the GARCH residuals tend to be heavy tailed. To accommodate this, we use the student's $t$ and GED distributions instead of the normal distribution when we employ the GARCH model (Mittnik et al., 2002). 


\section{Mll Macrothink}

International Journal of Accounting and Financial Reporting

ISSN 2162-3082

2019, Vol. 9, No. 4

Table 3 shows the coefficient estimates of the GARCH $(1,1)$ model for the returns of the three stock market indices we study. We use GARCH $(1,1)$ model since this model can capture the volatility shocks in financial time series data and treats positive and negative news identically. Another benefit of this model is that future variance is computed as a weighted average of the long-run variance, present squared return and present variance (Mathoera, 2016). Stock volatility in terms of latent character comprises the intra-day volatility as well as the variation between days. Unlike price, which is a flow variable and hence can be calculated directly, volatility is a stock variable and therefore has to be calculated over a period of time (Matei, 2009).

All the parameter estimates of the $\operatorname{GARCH}(1,1)$ model are significant at the $1 \%$ level. The estimates of $\alpha_{0}$ are all positive and significantly lower than the sample variances in Table 3. This is due to the changing conditional variances over time as well as their contribution to the unconditional variances. Our results furthermore show that the volatility in our sample is persistent. We find that the sum of $\alpha$ and $\beta$ in the GARCH $(1,1)$ model, ranges between 0.8810 to 0.9120 for our indices, with an average of 0.9015 . Since these figures are close to one, as in Tian and Guo (2006), we conclude that there are strong ARCH and GARCH influences in our data. This result indicates that the current volatility of the stock market returns in our sample can be estimated using past volatility, and this relationship continues over time. We find that the AIC/SIC values are smaller and negative for the unconstrained GARCH $(1,1)$ model, which shows the statistical stability of the model. The higher log-likelihood in GARCH $(1,1)$ model shows that this model performs better in explaining of conditional volatility over the sample period.

Table 3. GARCH $(1,1)$ model

\begin{tabular}{llll}
\hline & LNDJIA & LNSSE & LNSX \\
\hline$\omega$ & $0.0002 *[0.00]$ & $\begin{array}{l}0.0003^{*} \\
{[0.00]}\end{array}$ & $\begin{array}{l}0.0001^{*} \\
{[0.00]}\end{array}$ \\
\hline$\alpha$ & $0.1088^{*}$ & $0.0848^{*}$ & $0.0888^{*}$ \\
{$[0.00]$} & {$[0.00]$} & {$[0.00]$} \\
\hline$\beta$ & $0.8810^{*}$ & $0.9120^{*}$ & $0.9117^{*}$ \\
{$[0.00]$} & {$[0.00]$} & {$[0.00]$} \\
\hline$\alpha+\beta$ & 0.9898 & 0.9968 & 1.0005 \\
\hline AIC/SIC & $-1.78 /-1.77$ & $-0.59 /-0.59$ & $-1.11 /-.10$ \\
\hline Log likelihood & 4786.076 & 1604.671 & 2968.942 \\
\hline
\end{tabular}

This table shows the GARCH $(1,1)$ results for the stock market indices in our sample. Our sample consists of stock indices from US, China, and India. We take the natural logarithm of the daily prices of these indices and denote these prices as LNDJIA for Dow Jones Industrial 
Average (US), LNSSE for Shanghai Composite Index (China), and LNSX for Sensex (India). $\omega$ is the constant, $\alpha$ is the ARCH effect, and $\beta$ is the GARCH effect. *denotes significant at the $1 \%$. p-values are in square brackets. AIC is the Akaike Information Criterion and SIC is the Schwarz Information Criterion.

\subsubsection{EGARCH Model}

Exponential GARCH (EGARCH) model was developed by Nelson in 1991 and this model incorporates leverage effects. Brooks (2008) indicates that while the GARCH model imposes the nonnegative constraints on the parameters, the EGARCH model allows the parameters to be negative (as well as positive). In EGARCH, the conditional variance $h_{t}$ is an asymmetric function of the disturbances. EGARCH model is represented as:

$$
\log \left(h_{t}\right)=\alpha_{0}+\sum_{j=1}^{q} \beta_{j} \log \left(h_{t-j}\right)+\sum_{i=1}^{p} \alpha_{i}\left|\frac{u_{t=i}}{\sqrt{h_{t=i}}}\right|+\sum_{k=1}^{r} \gamma_{k} \frac{u_{t-k}}{\sqrt{h_{t-k}}}
$$

EGARCH allows positive and negative shocks $\left(\mu_{t}\right)$ to affect volatility. The exponential GARCH is asymmetric as the level $\left|\mu_{\mathrm{t}-1}\right| / \sqrt{\mathrm{h}} \mathrm{t}-\mathrm{i}$ is included with the $\gamma_{\mathrm{k}}$ coefficient. Since $\gamma_{\mathrm{k}}$ is usually negative, positive returns have a lower impact on volatility than negative returns (Bala and Premaratne, 2004). In the above equation, $\gamma_{\mathrm{k}}$ is the asymmetry parameter and shows the leverage effects. As a result, if the market experiences one-standard deviation of positive shock, the effect of the shock is $\alpha+\gamma$, while with a negative one-standard deviation shock the effect is $\alpha-\gamma$. If $\gamma_{\mathrm{k}}$ is negative, then we conclude that there is leverage effect in the

model and when $\gamma_{\mathrm{k}} \neq 0$ the model is asymmetric, indicating that lower returns in the market increase volatility.

In order to examine the leverage effect on volatility we use the EGARCH $(1,1)$ model. We hypothesize that the sign of gamma $(\gamma)$ in EGARCH $(1,1)$ will be negative and significant, indicating the existence of a leverage effect which indicates that negative returns have more influence on the conditional variance compared to positive returns. Table 4 shows that the gamma parameter $(\gamma)$ that is the indicator for asymmetric volatility, it is negative and significant at $1 \%$ level for all three stock markets we selected, demonstrating a strong leverage effect in these markets. This result is consistent with our hypothesis that positive returns result in lower volatility than negative returns and is consistent with Bala and Premaratne (2004). We also find that the coefficients of ARCH and GARCH are statistically significant at $1 \%$ level, and the sum of $\alpha$ and $\beta$ in the GARCH $(1,1)$ model ranges between 1.1307 and 1.1872, with an average of 1.1631. Since these values are greater than one, we find evidence of ARCH and GARCH influences on volatility. We find that AIC/SIC values are smaller and negative for the unconstrained EGARCH $(1,1)$ model, attesting to the stability of our model. The higher log-likelihood in EGARCH $(1,1)$ model shows that the model explains the conditional volatility well. 
Table 4. EGARCH $(1,1)$ model

\begin{tabular}{llll}
\hline & LNDJIA & LNSSE & LNSX \\
\hline$\omega$ & $-0.2459^{*}$ & $-0.1920^{*}$ & $-0.2241^{*}$ \\
{$[0.00]$} & {$[0.00]$} & {$[0.00]$} \\
\hline$\alpha$ & $0.1583^{*}$ & $0.1872^{*}$ & $0.2049^{*}$ \\
{$[0.00]$} & {$[0.00]$} & {$[0.00]$} \\
\hline$\beta$ & $0.9725^{*}$ & $0.9843^{*}$ & $0.9823^{*}$ \\
\hline$\alpha+\beta$ & {$[0.00]$} & {$[0.00]$} & {$[0.00]$} \\
\hline$\gamma$ & 1.1307 & 1.1714 & 1.1872 \\
\hline AIC/SIC & -0.1396 & -0.0331 & -0.0731 \\
\hline Log likelihood & $-1.83 /-1.82$ & $-0.61 /-0.60$ & $-1.12 /-1.11$ \\
\hline
\end{tabular}

This table shows the EGARCH $(1,1)$ results for the stock market indices in our sample. Our sample consists of stock indices from US, China, and India. We take the natural logarithm of the daily prices of these indices and denote these prices as LNDJIA for Dow Jones Industrial Average (US), LNSSE for Shanghai Composite Index (China), and LNSX for Sensex (India). $\omega$ is the constant, $\alpha$ is the ARCH effect, $\beta$ is the GARCH effect, and $\gamma$ is the leverage effect. *denotes significance at the $1 \%$ level. p-values are in square brackets. AIC is the Akaike Information Criterion and SIC is the Schwarz Information Criterion.

\subsubsection{TARCH (GJR-GARCH) Model}

The TARCH (also referred to as GJR-GARCH) model is an expansion of GARCH which adjusts for asymmetric responses of volatility to innovation fluctuations. Glosten, Jagananthan and Runkle (1993) developed the TARCH model that allows for conditional variances and diverse reactions to prior negative as well as positive innovations. We can represent TARCH as:

$$
h_{t}=\alpha_{0}+\sum_{i=1}^{q} \alpha_{i} u_{t-i}^{2}+\gamma_{i} u_{t-i}^{2} d_{t-1}+\sum_{i=1}^{p} \beta_{j} h_{t-j}
$$

where, $h_{t}$ is the conditional variance (one period forward forecast variance derived from past news) of the error term from the return equations, $\alpha_{0}$ is a constant, $\mu_{\mathrm{t}-\mathrm{i}}^{2}$ is the ARCH term showing the prior period squared error term from the return equations, $\mathrm{h}_{\mathrm{t}-\mathrm{j}}$ is the GARCH term showing the prior period conditional variance and $\mathrm{d}_{\mathrm{t}-1}$ is a dummy variable where: 


$$
d_{t-1}= \begin{cases}1 \text { if } u_{t-1}<0, & \text { bad news } \\ 0 \text { if } u_{t-1} \geq 0, & \text { good news }\end{cases}
$$

In the TARCH model, a positive improvement at time $\mathrm{t}$ has a shock on the volatility at time $\mathrm{t}+1$ equal to $\alpha$ times the residual squared, whereas a negative improvement has shock equal to $(\alpha+\gamma)$ times the residual squared. The existence of the leverage effect would indicate that the coefficient $\gamma$ is positive, i.e., a negative innovation has a larger shock than a positive innovation. The intuition of the model is as follows: if $\mu_{t-1}<0$, then $d_{t-1}=1$, and the consequence of the $\mu_{t-1}$ impact on volatility $h_{t}$ is represented with $\left(\alpha_{1}+\gamma_{1}\right) \mu^{2}{ }_{t-1}$. In contrast, if the impact is positive, then $\mu_{\mathrm{t}-1} \geq 0$ and $\mathrm{d}_{\mathrm{t}-1}=0$, and the result of the $\mu_{\mathrm{t}-1}$ impact on volatility $h_{t}$ is $\alpha_{1} \mu^{2}{ }_{t-1}$. Thus, if $\gamma_{1}>0$ the negative impact will have a bigger shock on volatility than the positive impact. The statistical significance of the $\gamma_{1}$ coefficient will establish whether there is a threshold effect on the conditional volatility. In this equation, we can see the impact of good information with the coefficient $\alpha_{i}$ and the impact of bad information with $\alpha+\gamma$. In addition, when $\gamma \neq 0$ we conclude that the impact of the news is asymmetric and when $\gamma>0$ leverage effect exists. Similar to GARCH, the parameter constraints of TARCH are $\alpha_{0}>0, \alpha_{i}>0, \beta \geq 0$ and $\alpha_{i}+\gamma_{i} \geq 0$. The coefficients still satisfy the constraints when $\gamma_{i}<0$ given that $\alpha_{i}+\gamma_{i} \geq 0$. When $\gamma_{i}<0$, upward swings in return have stronger influence on volatility than downward moves. Hence, we utilize the TARCH model to test for the leverage effect.

Table 5 shows that the gamma parameter $(\gamma)$ is positive and significant at $1 \%$ level. This result indicates that, consisting with our hypothesis, the leverage effects exists in all three stock markets we selected. We can estimate the extent of the influence of differential shocks on conditional variances using the estimates of $\alpha$ (ARCH effect) and $\gamma$ (leverage effect). For example, Table 5 shows that good information has a shock of $0.0627(\alpha)$ on the US stock market whereas bad information has a shock of $0.1459(\alpha+\gamma)$. The results indicate that a $1 \%$ increase in volatility will result in a $0.0831 \%$ change in the US market, $0.1254 \%$ in the Chinese market and $0.1015 \%$ in Indian market. Similarly, good information has a shock of 0.0677 on the conditional variance of the Chinese stock market whereas bad information has a shock of 0.1931 . For the Indian stock market, good information produces a shock of 0.0545 whereas the shock of bad information on the conditional variance is 0.1565 . These results indicate that the Chinese stock market is particularly susceptible to volatility movements as the leverage effect is highest for this market (Bala and Premaratne, 2004).

Our results show that the ARCH effect ( $\alpha$ ) is higher for the Chinese stock market than the US and Indian stock markets, which indicates that the impact of stock returns in previous periods on current market volatility lingers on longer for the former market. This result shows that the Chinese stock market has less information efficiency than US and Indian stock markets. The 
results also show evidence of ARCH and GARCH influences, as the sum of $\alpha$ and $\beta$ in the TARCH $(1,1)$ model ranges between 0.9583 and 0.9786 , are statistically significant, and have an average of 0.9639 (close to one). We find that AIC/SIC values are smaller and negative for the unconstrained TGARCH $(1,1)$ model, which shows that the model is statistically stable. The higher log-likelihood values indicate that the model explains the conditional volatility well over the sample period.

Table 5. TARCH $(1,1)$ model

\begin{tabular}{llll}
\hline & LNDJIA & LNSSE & LNSX \\
\hline$\omega$ & $0.0002^{*}$ & $0.0003^{*}$ & $0.0002^{*}$ \\
\hline$\alpha$ & $0.0627^{*}$ & $0.0677^{*}$ & $0.0550^{*}$ \\
\hline$\beta$ & $0.8956^{*}$ & $0.9110^{*}$ & $0.8999 *$ \\
\hline$\alpha+\beta$ & 0.9583 & 0.9786 & 0.9549 \\
\hline$\gamma$ & 0.0831 & 0.1254 & 0.1015 \\
\hline AIC/SIC & $-1.82 /-1.82$ & $-0.60 /-0.59$ & $-1.12 /-1.11$ \\
\hline Log likelihood & 4903.130 & 1613.650 & 3008.825 \\
\hline
\end{tabular}

This table shows the TGARCH $(1,1)$ results for the stock market indices in our sample. Our sample consists of stock indices from US, China, and India. We take the natural logarithm of the daily prices of these indices and denote these prices as LNDJIA for Dow Jones Industrial Average (US), LNSSE for Shanghai Composite Index (China), and LNSX for Sensex (India). $\omega$ is the constant, $\alpha$ is the ARCH effect, $\beta$ is the GARCH effect, and $\gamma$ is the leverage effect. *denotes significance at the $1 \%$ level. p-values are in square brackets. AIC is the Akaike Information Criterion and SIC is the Schwarz Information Criterion.

\section{Conclusions}

In this paper, we study the relationship between asset volatility and leverage for US, Chinese, and Indian stock markets. We use daily closing prices of the Dow Jones Industrial Average, Shanghai Composite Index, and BSE Sensex for the period of July 1, 1997 to November 22, 2018. We utilize ARCH, GARCH, GJR GARCH, and EGARCH models in our analysis. We find that Chinese stock markets have the highest volatility among the three stock markets while the US stock market has the highest average returns. Our results indicate that the unconditional correlation among these stock markets is significant and positive although the correlation values are low in magnitude. The correlation between the US and Chinese stock markets is lowest indicating that the portfolio diversification opportunities are highest when 
investors invest in these two stock markets. Our results show that past market volatility is a good indicator of future market volatility for our sample. The results also show that positive stock market returns result in lower volatility compared to negative stock market returns. All the parameters of our GARCH $(1,1)$ model are significant at the $1 \%$ level with $\alpha+\beta$ being close to one. In our EGARCH model, $\gamma$ is negative and significant at $1 \%$ for all three stock markets selected, indicating that positive returns result in lower volatility than negative returns. In our TARCH model the gamma parameter is positive and significant indicating that leverage exists in all three markets. We find that the Chinese stock market is less efficient than US and Indian stock markets since the impact of new information takes longer to be reflected in stock prices.

Future studies should expand on our research and study if the firm-specific factors such as the size, governance structure, and information asymmetry influence the leverage effect. Information on these factors are generally available to investors and as a result with this additional information investors can make better decisions. One of the limitations of our study is the lack of more current data. Future studies should also include this data in order to confirm that the relationships we have identified still hold.

\section{References}

Aboura, S., \& Chevallier, J. (2012). Leverage vs. Feedback: Which Effect Drives the Oil Market?. Retrieved from https://halshs.archives-ouvertes.fr/halshs-00720156/document

Albaity, M., \& Ahamed, R. (2011). Return performance, leverage effect, and volatility spillover in Islamic stock indices evidence from DJIMI, FTSEGII and KLSI. Investment Management and Financial Innovations, 8, 161-171.

Aydemir, A. C., Gallmeyer, M., \& Hollifield, B. (2006). Financial Leverage Does Not Cause the Leverage Effect. Working Paper, Carnegie Mellon University.

Aydemir, A. C., Gallmeyer, M., \& Hollifield, B. (2007). Financial Leverage and the Leverage Effect - A Market and Firm Analysis. Carnegie Mellon University.

Baele, L. (2005). Volatility spillover effects in European equity markets. Journal of Financial and Quantitative Analysis, 40, 371-401.

Bala, L., \& Premaratne, G. (2004). Volatility Spillover and Co-movement: Some New Evidence from Singapore. Retrieved from https://pdfs.semanticscholar.org/a681/9ced6f699ec74b615875f98dad3ef72839e8.pdf

Bittlingmayer, G. (2005). Oil and stocks: is it war risk. Working paper series, University of Kansas.

Black, F. (1976). Studies of stock price volatility changes. Proceedings of the 1976 Meetings of the Business and Economic Statistics Section, 177-181.

Bollerslev, T. (1986). Generalized Autoregressive Conditional Heteroskedasticity. Journal of Econometrics, 31, 307-327. 


\section{Mll Macrothink}

International Journal of Accounting and Financial Reporting ISSN 2162-3082 2019, Vol. 9, No. 4

Booth, G. G., Martikainen, T., \& Tse, Y. (1997). Price and Volatility Spillovers in Scandinavian Stock Markets. Journal of Banking and Finance, 21, 811-823.

Chelley-Steeley, P. L., \& Steeley, J. M. (2005). The Leverage Effect in the UK Stock Market. Applied Financial Economics, 15, 409-423.

Chorro, C., Guegan, D., Ielpo, F., \& Lalaharison, H. (2017). Testing for Leverage Effects in the Returns of US Equities. Documents de travail du Centre d'Economie de la Sorbonne.

Christie, A. (1982). The stochastic behavior of common stock variances - value, leverage, and interest rate effects. Journal of Financial Economic Theory, 10, 407-432.

Dahiru, A. B., \& Taro, T. (2017). Stock market's volatility spillovers during financial crises: A DCC-MGARCH with skewed-t density approach. Borsa Istanbul Review, 17, 25-48.

DeGennaro, B. (1990). Stock Returns and Volatility. Journal of Financial and Quantitative Analysis, 25, 203-214.

El Alaoui, A. O., Bacha O. I., Masiha, M., \& Asutay, M. (2017). Leverage versus Volatility: Evidence from the Capital Structure of European Firms. Economic Modelling, 62, 145-160.

Eleftherios, T., Yusuf, M., \& Erginbay, U. (2015).Comparison of Forecasting Volatility in the Czech Republic Stock Market. Applied Economics and Finance, 2, 11-18.

Engle, R. (1982). Autoregressive Conditional Heteroscedasticity with Estimates of the Variance of United Kingdom Inflation. Econometrica, 50, 987-1007.

Forbes, K., \& Rigobon, R. (2002). No Contagion, Only Interdependence: Measuring Stock Market Co-Movements. Journal of Finance, 57, 2223-2261.

Glosten, R. T., Jagannathan, R., \& Runkle, D. (1993). On the relation between the expected value and the volatility of the nominal excess return on stocks. Journal of Finance, 48, 1779-1801.

Guo, W., Wang, F. Y., \& Wu, H. (2011). Financial Leverage and Market Volatility with Diverse Beliefs. Econ Theory, 47, 337-364.

Inagaki, K. (2007). Testing for volatility spillover between the British pound and the euro. Research in International Business and Finance, 21, 161-174.

Jin, X. (2017). Time-Varying Return-Volatility Relation in International Stock Markets. International Review of Economics and Finance, 51, 157-173.

Krishnan, R., \& Mukherjee, C. (2010). Volatility in Indian Stock Markets: A Conditional Variance Tale Re-told. Journal of Emerging Market Finance, 9, 71-93.

Kristoufek, L. (2014). Leverage Effect in Energy Futures. Energy Economics, 42, 50-57. Retrieved from https://arxiv.org/abs/1403.0064

Lee, E., \& Han, D. B. (2016). Oil Price Volatility and Asymmetric Leverage Effects. Retrieved

from 
https://ageconsearch.umn.edu/record/235480/files/Oil_SV_20160523_For\%20AAEA_Final. pdf

Lithman, O. (2010). Leverage and Volatility. LUP Student papers, Department of Economics, Lund University.

Matei, M. (2009). Assessing Volatility Forecasting Models: Why GARCH Models Take the Lead. Romanian Journal of Economic Forecasting, 4, 42-65.

Mathoera, M. M. S. (2016). Does any model beat the GARCH (1.1)? A Forecast comparison of volatility models through option prices. Retrieved from https://pdfs.semanticscholar.org/61e6/6c567a8fde5d2623e991955cb0b262b5f92b.pdf

Mittnik, C. H. (2002). Forecasting Stock Market Volatility and the Informational Efficiency of the DAX-Index Options Market, European Journal of Finance, 8, 302-321.

Nikkinen, J., Sahlstrom, P., \& Vahamaa, S. (2006). Implied volatility linkages among major European currencies. Journal of International Financial Markets, Institutions and Money, 16, 87-103.

Okicic, J. (2014). An Empirical Analysis of Stock Returns and Volatility: The Case of Stock Markets from Central and Eastern Europe. South East European Journal of Economics and Business, 9, 7-15.

Pesaran, M. H., \& Pick, A. (2007). Econometric issues in the analysis of contagion. Journal of Economic Dynamics and Control, 31, 1245-1277.

Sjo, B. (2011). Estimation and testing for ARCH and GARCH. Retrieved from https://pdfs.semanticscholar.org/c5d9/c7c60c6a639660886a59dfca5a1c142df81f.pdf

Sood, V., \& Saluja, H. S. (2016). Unfolding Volatility and Leverage Effect: A Comparison of S\&P BSE Sensex and Nifty 50. Apeejay Journal of Management and Technology, 11, 1-13.

Tian, G., \& Guo, M. (2006). Intraday Return, Volatility and Liquidity: An investigation of the Market Microstructure of the Chinese Stock Exchange. Ph.D. Thesis submitted to the School of Economics and Finance, University of Western Sydney.

Triady, M. S., Kurniasari, R., Utami, A. F., \& Sofyan, M. I. (2016). Investigation of Leverage Effect in Indonesian Stock Market. International Journal of Economics and Management, 10, $1-17$.

Tripathy, N. (2017). Do BRIC Countries Stock Market Volatility Move Together? An Empirical Analysis of Using Multivariate GARCH models. International Journal of Business and Emerging Markets, 9, 104-123.

Turan, S. S. (2016). The Impact of Investor Sentiment on the "Leverage Effect". International Econometric Review, 1-18.

Xu, D., \& Li, Y. (2012). Empirical Evidence of the Leverage Effect in a Stochastic Volatility Model: A Realized Volatility Approach. Front Econ China, 7, 22-43. 


\section{Macrothink}

International Journal of Accounting and Financial Reporting ISSN 2162-3082 2019, Vol. 9, No. 4

Yalama, A., \& Sevil, G. (2009). Volatility-Expected Return and Leverage Effect in World Stock Exhange Markets. The Empirical Economic Letters, 8, 197-206.

\section{Note}

Note 1. More recent studies on the leverage effect and the asymmetry of news include Aydemir et al. (2006), Chorro et al. (2017), Booth et al. (1997), Albaity (2011), Engle et al. (1990), Forbes and Rigobon (2002), Baele (2005), Bittlingmayer (2005), Pesaran and Pick (2007), Nikkinen et al. (2006), Inagaki (2007), Lee and Han (2016), Black (1976), Christie (1982), DeGennaro (1990).

\section{Copyright Disclaimer}

Copyright for this article is retained by the author(s), with first publication rights granted to the journal.

This is an open-access article distributed under the terms and conditions of the Creative Commons Attribution license (http://creativecommons.org/licenses/by/4.0/) 